\title{
PGP expression in Cooperia oncophora before and after ivermectin selection
}

\author{
Marlene Areskog • Annie Engström • Jonas Tallkvist • \\ Georg von Samson-Himmelstjerna • Johan Höglund
}

Received: 18 January 2013 / Accepted: 21 May 2013 /Published online: 15 June 2013

(C) The Author(s) 2013. This article is published with open access at Springerlink.com

\begin{abstract}
The aim of this study was to investigate genetic selection and P-glycoprotein (PGP) expression in three different isolates of Cooperia oncophora before treatment and after ivermectin (IVM) injection. Adult parasites were recovered from nine calves experimentally infected with the isolates represented by one IVM susceptible laboratory isolate, and two field isolates showing signs of phenotypic macrocyclic lactone resilience according to the faecal egg count reduction test. Five males and five females per isolate were examined both pre- and post-IVM treatment giving a total of 60 worms. A sequence from C. oncophora (Con-pgp) was identified, showing $83 \%$ similarity to Pgp-9 of Caenorhabditis elegans. Primers specific to putative Con-pgp-9 mRNA were designed, generating a 153-bp PCR product. Total RNA was prepared from all worms, and Con-pgp-9 expression was measured by quantitative real-time reverse transcription PCR. Our results showed that mean PGP concentrations were four to five times higher in female as compared to male worms. No significant differences in gene expression between experimental groups pre- and post-IVM selection were detected. However, PGP gene expression tended to be increased by IVM treatment in male worms $(p=0.091)$, with $70 \%$ higher mean expression in
\end{abstract}

\section{Areskog · A. Engström · J. Höglund $(\square)$}

Department of Biomedical Sciences and Veterinary Public Health

(BVF), Section for Parasitology, Swedish University of Agricultural

Sciences, Box 7028, SE-750 07 Uppsala, Sweden

e-mail: johan.hoglund@slu.se

M. Areskog

e-mail: marlene.areskog@slu.se

J. Tallkvist

BVF, Division of Pathology, Pharmacology and Toxicology, SLU, Uppsala, Sweden

G. von Samson-Himmelstjerna

Institute for Parasitology and Tropical Veterinary Medicine, Freie

Universität, Berlin, Germany treated than in untreated male worms. Amplified fragment length polymorphism analysis did not demonstrate any bottleneck effect within the different isolates post-treatment. The total mean gene diversity values were 0.158 and 0.153 before and after treatment, respectively. Inbreeding coefficient in subpopulations compared to total population $F_{\mathrm{ST}}$ was 0.0112 , suggesting no genetic differentiation between or within the investigated isolates in relation to treatment. In conclusion, comparison of Con-pgp-9 expression showed no significant difference before and after treatment, but some tendency towards increasing expression in male worms.

\section{Introduction}

Infections with parasitic gastrointestinal nematodes (GIN) are common among grazing cattle worldwide, and may cause serious economic losses due to decreased growth of their hosts (Sutherland and Leathwick 2011). In Sweden, the most important GIN species include Cooperia oncophora (Fig. 1) and the more pathogenic Ostertagia ostertagi, which usually are present as mixed infections in grazing cattle (Höglund 2010). Regular strategic treatment with anthelmintic drugs, as topical or injectable formulations, remains the principal means of control of helminth infections (Prichard et al. 2007). Lately, reports have shown that a worldwide spread of anthelmintic resistance (AR) has occurred, probably due to an extensive usage of anthelmintics in the cattle livestock industry (Demeler et al. 2009; Gasbarre et al. 2009; Sutherland and Leathwick 2011). However, the underlying mechanisms of AR development in cattle nematodes remain essentially unknown. It is understood that drug resistance can arise in four different ways: a change in the molecular target causing failure at the binding site, changes in drug metabolism preventing activation or removing the drug, changes in drug distribution in the target organism, or amplification of 


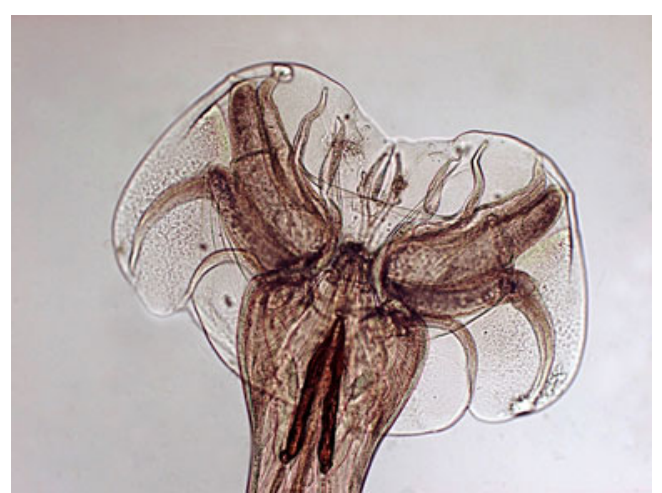

Fig. 1 C. oncophora, bursa and spicules of adult male

target genes that overcome drug action (Wolstenholme et al. 2004).

Ivermectin (IVM) is one of several anthelmintics in the group of macrocyclic lactones (ML), which has been extensively used in the control of parasitic nematodes of livestock since they were introduced in the early 1980s (Omura 2008). MLs act through irreversible binding to $\gamma$-aminobutyric acidand glutamate-gated chloride $(\mathrm{GluCl})$ channels, causing hyperpolarisation and thus paralysis of pharyngeal and somatic muscle cells, leading to starvation and expulsion of worms from the GI tract (Blackhall et al. 1998b, 2003; Martin et al. 1998; Rana and Misra-Bhattacharya 2013). It has been shown for the model organism Caenorhabitidis elegans (Cully et al. 1994; Dent et al. 2000; Lynagh and Lynch 2010; McCavera et al. 2007) as well as for C. oncophora (Njue et al. 2004) that IVM resistance can be associated with mutations in $\mathrm{GluCl}$, resulting in receptor conformation changes and lowered sensitivity to IVM. However, the mechanisms behind IVM resistance are complex, and there are many studies that suggest the involvement of P-glycoproteins (PGP). PGPs are part of a larger superfamily of transmembrane efflux transporters that have been implicated as a primary cause of anthelmintic resistance both in $C$. elegans and in the abomasal sheep nematode Haemonchus contortus (Blackhall et al. 1998a; James and Davey 2009; Kerboeuf et al. 2003a). PGPs, for which IVM is a well-known substrate (Kerboeuf and Guegnard 2011; Lespine et al. 2008), are members of the ATP binding cassette (ABC) superfamily of genes coding for molecules involved in active transport of endo- and exogenous hydrophobic molecules (Jones and George 2005). Dupuy et al. (2010) showed that PGPs are involved in the pharmacokinetics of IVM, and recently Kerboeuf and Guegnard (2011) found evidence that MLs activate transport activity in nematode PGP, and suggest that several substituents in the ML structure are involved in modulating the stimulatory effect. Altogether, 14 isoforms of PGP plus 1 pseudogene have been annotated in the C. elegans genome database (WormBase, version: WS234).

The majority of ML-resistance studies to date have investigated target site mutations. Some attention has been paid to the role of changes in gene expression, and upregulation in helminth PGP gene expression has been suggested to enhance the parasite's ability to survive exposure to IVM. The potential effect of this may be an increased membrane transport and thus faster drug elimination. Recently, PGP expression from several variants of PGP in Teladorsagia circumcincta from sheep was investigated in IVM-resistant isolates (Dicker et al. 2011). One of the PGP, Tci-Pgp-9, showed increased expression at the mRNA level and nucleotide sequences also showed high levels of polymorphism, which could play an important role in helminth survival of IVM exposure. Pachnicke (2009) performed similar studies in a benzimidazole (BZ)-selected $O$. ostertagi population and found evidence of increased PGPrelated signals in eggshells from BZ-selected $O$. ostertagi, but no signs of increased PGP gene expression in adult worms.

In the summers of 2006 and 2007, the efficacy of ML (Ivomec inj. ${ }^{\circledR}$ ) was investigated in five cattle herds in the Uppsala region of central Sweden (Demeler et al. 2009). The evaluation was made among first season grazing (FSG) cattle some weeks after turnout, and was conducted using the faecal egg count reduction test (FECRT). It showed unsatisfactory efficacy results, with only one farm reaching acceptable reductions of egg output in 2006. In 2007, the reduction was insufficient on all farms where animals were treated with IVM. Isolates from two of these farms were collected, and a pen trial was carried out to investigate the effect of injectable IVM under controlled conditions (unpublished data, Areskog et al.). The objectives of the current study were to further characterise the recovered worms in vitro and to compare PGP expression in adult worms before and after treatment.

\section{Materials and methods}

\section{Parasites}

During 2009, an IVM selection trial was carried out where three groups, each of 11 FSG, were experimentally inoculated with mixtures of 40,000 infective third stage (L3) larvae of $C$. oncophora and $O$. ostertagi. The study in its entirety will be presented in a separate publication, but in brief, control group A received an equal mixture of $\mathrm{L} 3$ from each of two laboratory isolates from Tierärztliche Hochschule, Hannover, originating from the Central Veterinary Laboratory at Weybridge, UK. Both isolates had no history of being refractory to treatment with any anthelmintics in vitro (Demeler et al. 2010). Calves in groups B and C were inoculated with mixed L3 isolated from the Swedish farms showing poor reductions to IVM according to FECRT: $84 \%$ [95 \% confidence interval (CI), 67-95] and $85 \%$ (62-99) reductions, respectively, at day 7 (Demeler et al. 2009). All animals were injected with IVM at the standard dose rate of $0.2 \mathrm{mg}$ IVM per $\mathrm{kg} 35$ days postinfection (d.p.i). Four days before IVM treatment (31 d.p.i), 
one animal per group (A, B and C) was euthanized intravenously with pentobarbital (ex tempore $300 \mathrm{mg} / \mathrm{ml}, 60 \mathrm{ml} / \mathrm{calf}$ ). Another two animals per group were euthanized 10 days postIVM treatment (45 d.p.i). Individual faecal samples were also collected rectally at the day of slaughter. A modified McMaster method (Anonymous 1986) was used to determine the number of parasite eggs in $3 \mathrm{~g}$ of faeces, giving a diagnostic sensitivity of 50 eggs per gram faeces (EPG). Animals were treated, and the trial was performed according to formal institutional ethical approval (C276/8).

At slaughter, worms were basically recovered according to Larsson et al. (2007). Briefly, the abomasum and $\sim 7 \mathrm{~m}$ of the proximal small intestine (duodenum, jejunum) were separated, and their content emptied into individual vessels. The mucosal surfaces were washed with tap water, and from each animal, five male and five female adult worms were immediately recovered and stored at $-80{ }^{\circ} \mathrm{C}$ in individual Eppendorf tubes until analysis. In addition, 20-ml aliquot subsamples were collected and stored at $-20{ }^{\circ} \mathrm{C}$ for worm counts and additional analysis. Also, the abomasal mucosa was scraped off and digested in a pepside solution for $O$. ostertagi recovery.

\section{Isolation of RNA}

Total worm RNA was isolated, using Macherey-Nagel NucleoSpin RNA II columns with DNAse I, individually from five single male and five female $C$. oncophora each pre- and post (10 days) IVM treatment, from three different isolates, giving in total 60 worms. The three isolates represented the propagated susceptible control group plus two isolates showing signs of phenotypic clinical ML resistance according to previous FECRT results. Washing buffers and rDNAse buffer were used to remove contaminating DNA, and integrity of the RNA was checked visually following electrophoresis. Eluates were kept frozen at $-80{ }^{\circ} \mathrm{C}$ for long-term storage. RNA quantification was performed according to the RiboGreen protocol (Invitrogen) using aVictor2 1420 Multilabel counter (Wallac).

\section{Primer design}

A conserved 202-bp PGP sequence from C. oncophora (Pachnicke 2009) was identified by ClustalW2 as having $83 \%$ similarity to the $P G P-9$ of $C$. elegans. Primers specific to this conserved PGP sequence were then designed in Primer3, generating a 153-bp PCR product. Sequencing of the PCR product was performed, followed by a BLAST search in Wormbase (genome view), which was identified as WBGene00004003.

\section{RT-qPCR}

One-tube RT-PCR QuantiTect with SYBR Green (Qiagen) was used to measure PGP gene expression by RT-qPCR using known concentrations of PGP-PCR product as standards and non-template controls as blanks. The primer sequences used were C. elegans Pgp-9 Forward 5' CGA ACG AGG TGT GCA ACT AA $3^{\prime}$ and $C$. elegans Pgp-9 Reverse 5' GCC TTC TCC AAA GCT TCT TGT $3^{\prime}$. The 25- $\mu$ l RT-PCR reactions contained $12.5 \mu \mathrm{l} 2 \times$ QIAGEN Quanti Tect SYBR Green master mix, $0.5 \mu \mathrm{l}$ Forward primer $(10 \mu \mathrm{M}), 0.5 \mu \mathrm{l}$ reverse primer $(10 \mu \mathrm{M}), 0.25 \mu \mathrm{l}$ Q-RT, $1.25 \mu \mathrm{l}$ of RNAse-free $\mathrm{H}_{2} \mathrm{O}$ and $10 \mu \mathrm{l}$ RNA sample adjusted to contain 2 ng total RNA from each single worm. Thus, PGP expression was normalised to the amount of total RNA in the PCR reaction as previously described by Tyden et al. (2009). All samples were run in technical duplicates. To determine the level of expression of PGPs before and after treatment, a standard curve was applied using five concentrations of the purified and sequenced $153 \mathrm{bp}$ PGP-PCR product diluted from 7,000 to $0.7 \mathrm{ag}^{-1} \mathrm{l}^{-1}$ in tenfold titrations. The PGP-PCR product was quantified by applying PicoGreen reagent (Invitrogen) according to the instructions of the manufacturer and a Victor2 1420 Multilabel counter (Wallac). To minimise the risk of amplifying genomic DNA, the samples were DNAse treated during RNA isolation, as previously described.

RNA samples were run in a Rotor-Gene 3000 (Corbett) and the data analysed using Rotor-Gene 6.1.90 software (Corbett). The RT-qPCR conditions were as follows: RT step, $50{ }^{\circ} \mathrm{C}$ for $30 \mathrm{~min}$; Taq-polymerase activation step, $95^{\circ} \mathrm{C}$ for $15 \mathrm{~min}$ followed by 45 cycles of $94^{\circ} \mathrm{C}$ for $60 \mathrm{~s}, 55^{\circ} \mathrm{C}$ for $60 \mathrm{~s}$ and $68{ }^{\circ} \mathrm{C}$ for $45 \mathrm{~s}$ and a final extension step at $68{ }^{\circ} \mathrm{C}$ for $7 \mathrm{~min}$. Melting curve analysis was performed for each sample in direct connection to the PCR, to verify that no secondary products were generated. To quantify the relative changes in expression of putative Con-pgp-9 before and after IVM treatment, the $2^{-\Delta C T}$ method of Livak and Schmittgen (2001) was used. In addition, in order to measure absolute Con-pgp-9 expression, absolute gene concentrations were also calculated from the standard curve.

Amplified fragment length polymorphism

\section{DNA extraction}

DNA was prepared from individual worms using a QIAamp DNA Micro Kit (Qiagen) according to the manufacturer's recommendation. Samples were eluted in $30 \mu \mathrm{l}$ buffer AE. Treatment with RNaseA was performed post-DNA isolation by adding $60 \mu \mathrm{g}$ of RNaseA to $30 \mu \mathrm{l}$ of sample and incubating for $5 \mathrm{~min}$ at room temperature to obtain RNA-free samples. The purified DNA was stored at $-20{ }^{\circ} \mathrm{C}$ until use.

\section{AFLP procedure}

In total, 108 adult $C$. oncophora of both sexes were used for AFLP analysis, but unlike the worms used for gene expression 
studies, these were recovered from aliquots frozen at $-18{ }^{\circ} \mathrm{C}$ (Table 1). The AFLP procedure was performed basically as described by Applied Biosystems (ABI) in their Plant Mapping Protocol and in accordance with Höglund et al. (2004). All reagents were supplied in the AFLP ${ }^{\circledR}$ Plant Mapping Kit (ABI), except for the restriction enzymes and the T4 DNA ligase, which were purchased from New England BioLabs. For all worms, the maximum allowed volume, $5.5 \mu \mathrm{l}$, of extracted DNA was used. The DNA from each individual worm was digested with 1 unit of MseI and 5 units of EcoRI, and MseI adaptor and EcoRI adaptor were ligated in the same reaction as the digestion. After the restriction-ligation reaction, the mixture was diluted to a total volume of $50 \mu \mathrm{l}$ with $\mathrm{TE}_{0.1}$ (20 mM Tris-HCl, $0.1 \mathrm{mM}$ EDTA, pH 8.0). From the restriction-ligation reaction, $4 \mu \mathrm{l}$ of the diluted DNA was mixed with $1 \mu \mathrm{l}$ of the $\mathrm{ABI}$ pre-selective primer pairs $(5 \mu \mathrm{M})$ and $15 \mu \mathrm{l}$ of ABI's Core Mix for pre-selective amplification. The amplified products were diluted to a final volume of $200 \mu \mathrm{l}$. The FAM dyed EcoRI-ACA+MseI-CTC primer combination was used for selective amplification. From the selective amplification products, $1.0 \mu \mathrm{l}$ was mixed with $9.6 \mu \mathrm{l}$ deionised formamide and $0.4 \mu \mathrm{l} \mathrm{GeneScan-500} \mathrm{size} \mathrm{standard}$ (ABI). The mixture was denaturated for $3 \mathrm{~min}$ at $95^{\circ} \mathrm{C}$, before being loaded onto the ABI Prism 3100 Genetic Analyzer and analysed using GeneMapper analysis software 4.0.

\section{Statistical analysis}

Data were summarised in Microsoft Excel (2007), whereas statistical analyses and graphs were done in Minitab (version 15). Gene expression was analysed by sex using both $\log$ transformed- and original concentrations, and where we compared duplicate mean concentrations, before and after treatment with two sample $t$ tests. In addition, a three-factor ANOVA (GLM) comparing treatment $\times$ isolate $\times$ sex, with isolate as a random factor, was performed. The significance level was set to $p<0.05$.

The estimates of allele frequencies for each isolate used the Bayesian method with informative priors of Zhivotovsky (1999). The calculation of genetic diversity $\left(H_{\mathrm{j}}\right)$ and population structure $\left(F_{\mathrm{st}}\right)$ from these estimates followed the procedures of Lynch and Milligan (1994), with 2,000 randomizations used for the statistical tests. These statistics were all computed using the AFLPSurvey program of Vekemans (2002)

\section{Results}

Parasites

Faecal egg counts revealed patent infections in all animals at slaughter, both pre-treatment and 10 days post-IVM treatment (Table 1). At necropsy, mainly low to moderate numbers of $C$. oncophora remained in the small intestines of all IVM-treated animals (Table 1). The worm burden showed large variation within groups and no significant difference $(p=0.510)$ between groups.

\section{RT-qPCR}

The expression of the putative Con-pgp- 9 before treatment was compared to the results after treatment for each isolate, and males and females separately. Reaction efficiency of the

Table 1 EPG data from day of slaughter and estimated numbers of adult worms recovered in $20 \mathrm{ml}$ subsamples at necropsy, from calves before and 10 days after injection with ivermectin (Ivomec ${ }^{\circledR}$, Merial) at a dose rate of $0.2 \mathrm{mg}$ IVM/kg

\begin{tabular}{|c|c|c|c|c|c|c|c|}
\hline \multirow[t]{2}{*}{ Treatment } & \multirow[t]{2}{*}{ Calf } & \multirow[t]{2}{*}{ Origin } & \multicolumn{2}{|c|}{ O. ostertagi } & \multicolumn{2}{|c|}{ C. oncophora } & \multirow[t]{2}{*}{ EPG } \\
\hline & & & Males & Females & Males & Females & \\
\hline \multirow[t]{3}{*}{ Before IVM } & A1 & TiHo & 2,070 & 3,230 & 6,470 & 5,270 & 750 \\
\hline & B1 & Gråmunkehöga & 570 & 670 & 9,070 & 13,600 & 1,000 \\
\hline & $\mathrm{C} 1$ & Kolsta & 900 & 2,900 & 1,930 & 3,070 & 400 \\
\hline \multirow[t]{6}{*}{ After IVM } & A2 & TiHo & 0 & 0 & 3,330 & 5,730 & 150 \\
\hline & A3 & TiHo & 0 & 0 & 130 & 400 & $<50$ \\
\hline & B2 & Gråmunkehöga & 0 & 0 & 6,000 & 6,200 & 50 \\
\hline & B3 & Gråmunkehöga & 100 & 0 & 200 & 200 & $<50$ \\
\hline & $\mathrm{C} 2$ & Kolsta & 0 & 0 & 600 & 1,600 & $<50$ \\
\hline & $\mathrm{C} 3$ & Kolsta & 0 & 0 & 1,000 & 2,000 & $<50$ \\
\hline
\end{tabular}

Calves were previously each inoculated with a mixture of 40,000 L3 of $C$. oncophora and $O$. ostertagi, representing isolates with different deworming history. Calves A1, A2 and A3 were inoculated with equal mixtures of laboratory-maintained C. oncophora and $O$. ostertagi from TiHo, whereas B1, B2, B3, C1, C2 and C3 were inoculated with cattle nematodes from two different farms in Uppland, Sweden, showing phenotypic clinical IVM resistance in previous field trials. Ten worms from each calf were immediately recovered and stored separately at $-80{ }^{\circ} \mathrm{C}$ for RT-qPCR, and excessive worms were stored at $-20^{\circ} \mathrm{C}$ for AFLP analysis 
qPCR was 1.08 in females and 0.97 in males. All samples had concentrations within the range of the standard curve, and female worms had an approximately five times higher gene expression compared to male worms before treatment (Table 2).

The RT-qPCR results demonstrated that mean putative Con-pgp-9 expression in ML-treated male worms was $70 \%$ higher than in the untreated worms, with mean concentrations of $27( \pm 25) \mathrm{ag} \mu \mathrm{l}^{-1}$ before treatment and 46.2 $( \pm 32)$ ag $\mu l^{-1}$ after treatment, respectively (Table 2). Although mean concentrations and boxplots (Fig. 2) suggested a tendency for increased Con-pgp-9 gene expression after treatment, the statistical analysis showed no significant difference $(p=0.091)$.

In females, mean concentrations of PGP were $172( \pm$ SD of 124) ag $\mu \mathrm{l}^{-1}$ before treatment and $196( \pm 250) \mathrm{ag} \mu \mathrm{l}^{-1}$ after treatment (Table 2). However, as with the male worms, no significant difference $(p=0.747)$ in concentrations was seen in comparisons between any group pre- and post-selection (Fig. 3).

The two-sample $t$ test showed large variance within female worm groups. Comparing sex and treatment gave no significance ( $p=0.091$ and $p=0.747$, respectively), but the three-factor ANOVA, with isolate as a random factor, showed that the isolates behaved very differently $(p=0.006)$. Log transformed concentrations gave similar results (data not shown).

\section{AFLP}

AFLP showed no bottleneck effect within the population after treatment, with mean gene diversity $\left(H_{\mathrm{j}}\right)$ values of 0.158 before treatment and 0.153 after treatment (Table 3 ). Inbreeding coefficient $\left(F_{\mathrm{ST}}\right)$ in subpopulations compared to the total population was 0.0112 .

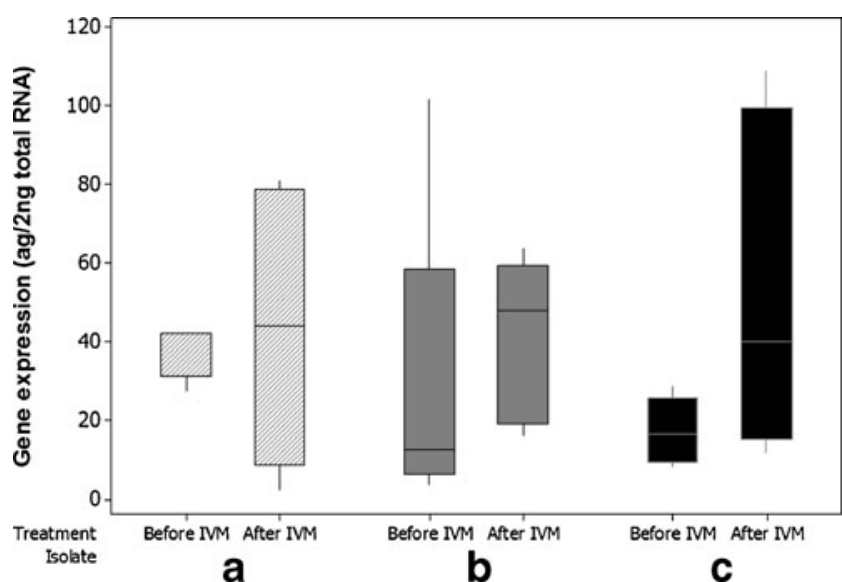

Fig. 2 Boxplot of quantitative putative Con-pgp- 9 expression, males, all groups, 15 worms before- and 15 worms after selection. Isolate $\mathrm{A}$ was propagated IVM susceptible, whereas B and C were two different field isolates showing phenotypic clinical IVM resistance in field trials

\section{Discussion}

In closely related GI nematodes of sheep, ML resistance has been suggested to be linked to an overexpression of PGPs (Blackhall et al. 1998a; Dicker et al. 2011; Williamson et al. 2011). Our hypothesis in this study was that changes in expression of efflux pumps such as PGPs would be affected in $C$. oncophora, which survive ML treatment, and/or in isolates with different deworming histories. Increased expression of this molecule has previously been suggested to play a role in drug resistance towards malaria, HIV and cancer, and in nematodes, it has been connected to ML resistance (Gupta and Gollapudi 1993; James and Davey 2009; Loo and Clarke 1999; Xu et al. 1998). Unlike most studies previously performed, we made an attempt to measure PGP expression levels in individual adult worms of $C$.

Table 2 RT-qPCR results showing concentrations of putative Con-pgp-9 RNA expression (ag/2 ng total RNA) in isolates before and 10 days after selection with injectable ivermectin at a dose rate of $0.2 \mathrm{mg}$ ivermectin $/ \mathrm{kg}$ body weight

\begin{tabular}{|c|c|c|c|c|c|c|c|c|c|}
\hline \multirow[b]{2}{*}{ Isolate } & \multicolumn{5}{|l|}{ Females } & \multicolumn{4}{|l|}{ Males } \\
\hline & & Median & Mean & $\mathrm{SD}$ & Sign. $p(95 \% \mathrm{CI})$ & Median & Mean & SD & Sign. $p(95 \% \mathrm{CI})$ \\
\hline \multirow[t]{2}{*}{ All } & Before & 153 & 172 & 124 & & 20 & 27 & 25 & \\
\hline & After & 83 & 196 & 250 & 0.747 & 44 & 46 & 32 & 0.091 \\
\hline \multirow[t]{2}{*}{$\mathrm{A}$} & Before & 122 & 121 & 38 & & 42 & 39 & 7 & \\
\hline & After & 458 & 420 & 343 & 0.125 & 44 & 44 & 35 & 0.764 \\
\hline \multirow[t]{2}{*}{$\mathrm{B}$} & Before & 155 & 154 & 37 & & 13 & 29 & 41 & \\
\hline & After & 83 & 108 & 65 & 0.213 & 48 & 41 & 21 & 0.571 \\
\hline \multirow[t]{2}{*}{$\mathrm{C}$} & Before & 301 & 242 & 203 & & 17 & 17 & 9 & \\
\hline & After & 55 & 60 & 33 & 0.119 & 40 & 54 & 43 & 0.137 \\
\hline
\end{tabular}

Group A was infected with a propagated IVM-susceptible laboratory isolate, and groups B and C were infected with two different field isolates showing phenotypic clinical IVM resistance in field trials 


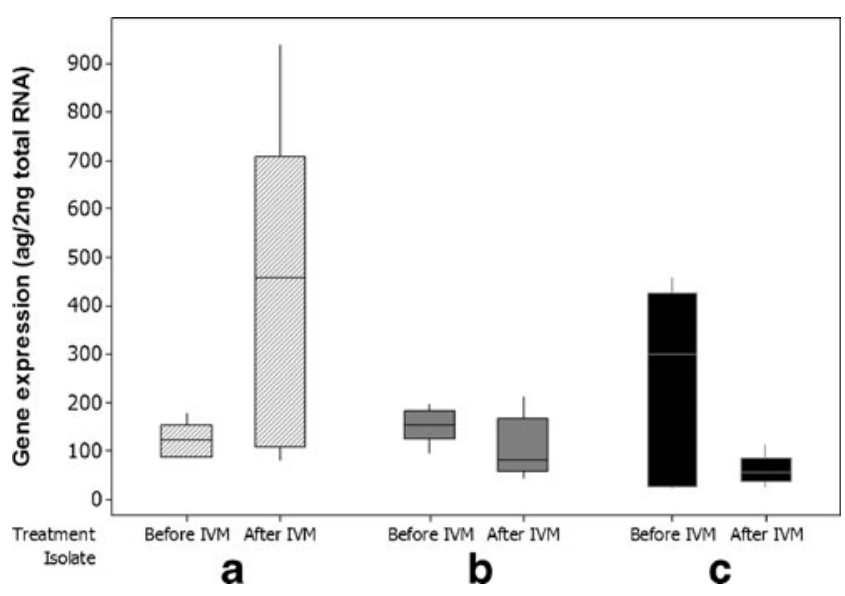

Fig. 3 Boxplot of quantitative putative Con-pgp-9 expression, females, all groups, 15 worms before- and 15 worms after selection. Isolate A was propagated IVM susceptible, whereas $\mathrm{B}$ and $\mathrm{C}$ were two different field isolates showing phenotypic clinical IVM resistance in field trials

oncophora, employing replicates reflecting the biological diversity in PGP expression. Our results demonstrate a wide distribution and no statistically significant differences in Con-pgp-9 expression pre- and post-IVM treatment.

It has previously been reported that several anthelmintics may cause an augmented PGP expression in various nematodes (Pachnicke 2009; Williamson et al. 2011; Dicker et al. 2011). The reasons for the discrepancy between our results and the ones previously reported are speculative. However, one possible explanation may include analyses of pooled samples missing the biological diversity by performing statistics on technical repeats. Also, use of BZ instead of IVM may influence the PGP expression in a different manner, or worm-specific sensitivity in the

Table 3 AFLP results derived from adult worms showing high gene diversity $\left(H_{\mathrm{j}}\right)$ values ranging between 0.139 and 0.169 in isolates before and 10 days after selection with injectable IVM at a dose rate of $0.2 \mathrm{mg}$ $\mathrm{IVM} / \mathrm{kg}$

\begin{tabular}{llllll}
\hline Isolate & Sex & $N$ & $H_{\mathrm{j} \text { before }}$ & $n$ & $H_{\mathrm{j} \text { after }}$ \\
\hline $\mathrm{A}$ & $\mathrm{M}$ & 7 & 0.16853 & 9 & 0.14800 \\
& $\mathrm{~F}$ & 8 & 0.15319 & 13 & 0.16727 \\
$\mathrm{~B}$ & $\mathrm{M}$ & 9 & 0.15288 & 10 & 0.13926 \\
& $\mathrm{~F}$ & 8 & 0.16733 & 9 & 0.15734 \\
$\mathrm{C}$ & $\mathrm{M}$ & 8 & 0.14704 & 9 & 0.15325 \\
& $\mathrm{~F}$ & 5 & 0.15879 & 13 & 0.15225 \\
& & 45 & $\mathbf{0 . 1 5 7 9 6}$ & 63 & $\mathbf{0 . 1 5 2 8 9 5}$
\end{tabular}

Isolate A was propagated IVM susceptible, whereas B and C were two different field isolates showing phenotypic clinical IVM resistance in field trials. Average within-population genetic diversity, measured as expected heterozygosity or gene diversity; before and after is equal $\left(H_{\mathrm{j}}\right.$ $=0.158$ before and 0.153 after) and thus negatively related to population bottleneck effect. $F_{\text {st }}$ (inbreeding coefficient) due to non-random mating in subpopulations relative to the total population, where $0=$ no differentiation and $1=$ complete differentiation, is low (0.0112), suggesting very little differentiation; $F_{\text {st }}=0.0112$ upregulation of PGP. Thus, it cannot be excluded that $C$. oncophora responds differently to anthelmintic treatment than O. ostertagi (Pachnicke 2009), H. contortus (Williamson et al. 2011) and T. circumcincta (Dicker et al. 2011). It is also often hypothesized that anthelmintic exposure itself induces expression of $\mathrm{ABC}$ transporter genes in nematodes, experimental evidence is still scarce (Ardelli and Prichard 2008; James and Davey 2009).

The results showed no significant differences before and after ML treatment between the three $C$. oncophora isolates (A, B and C), each with a different deworming history, possibly due to small sample sizes. However, there was a tendency towards increasing putative Con-pgp-9 expression in male worms $(p=0.091)$. Female worms seemed to give higher and more variable results $(p=0.747)$ than male worms, possibly due to the presence of varying amounts of eggs also expressing PGP (Kerboeuf et al. 2003b; Riou et al. 2005). The nonsignificant statistical results in the comparisons between sex and treatment might be a result of different expression patterns in the investigated isolates. For instance, females in groups B and $\mathrm{C}$ actually reduced their mean Con-pgp- 9 expression after ML treatment. This was in contrast to all the other groups and, hypothetically, it could be explained by a decrease in intrauterine egg production, and thus lower mRNA levels for expression of PGP in egg shells during IVM influences. It has previously been shown that the nematode uterine muscle is one of the most susceptible target organs for MLs (Prichard 2001), which could mean that the drug may temporarily suppress egg laying even though adult worms survive treatment. This would make fecund female worms unsuitable for investigation as it causes difficulties in distinguishing between worm- and egg PGP expression levels. However, the same situation did not seem to occur among females in the lab isolate, group A. The differences between groups, rather than differences before or after treatment, were also confirmed by statistical analysis. Clearly, a larger sample size is required to better ensure the effect of ML on individual worms, but the sampling method is both labor-intensive, expensive and demands euthanizing of animals to collect large number of adults surviving deworming. Sometimes we also had problems to isolate enough RNA from the worms, especially from the males, and the number of surviving worms was limited.

Our results therefore can neither support nor exclude that Con-pgp-9 is involved in the increased incidence of resistance to IVM in this cattle nematode, as has recently been reported for T. circumcincta in sheep (Dicker et al. 2011). Another factor that may explain the differing results is the time of sampling. Pachnicke (2009) collected worms 7 days post-treatment, while in other studies, it is unclear when donor animals were sacrificed. In this study, we investigated worms 10 days posttreatment; however, it is not known when would be the best time to measure changes in Con-Pgp-9 expression after ML treatment. In a most recently published investigation conducted in parallel to this, De Graef et al. (2013) examined effects of 
IVM treatment on the transcription of $C$. oncophora PGPs. In agreement with our findings, no significant differences with respect to Con-Pgp-9 expression were recorded between adults of susceptible and IVM-resistant Belgian C. oncophora isolates. Neither could any differences be seen between adults from the resistant isolate being ML-exposed or unexposed. However, in the latter adult worms, a 3.1- and 4.7-fold increased expression of Con-Pgp-11 was encountered in association with IVM and moxidectin, respectively, after in vivo exposure. Further experiments are thus clearly required to verify the results obtained in the present study, but also to elucidate additional resistance mechanisms that may be involved.

When our C. oncophora isolates were analysed with AFLP, we found no evidence of genetic bottlenecking in either of the drug-selected worms, and by comparing their genetic makeup pre- and post-treatment. In veterinary parasitology, AFLP has previously been used mainly to compare the genetic structures of various parasitic nematodes of livestock with different geographic backgrounds (Höglund et al. 2012, 2006; Nejsum et al. 2005; Troell et al. 2006), but also to compare consecutive stages of increased benzimidazole- and levamisole-resistant isolates during selection (Otsen et al. 2001). Höglund et al. (2006) concluded that most nematodes of domesticated hosts usually have very little genetic difference between populations, and are characterised by strong gene flow and expanding populations. In accordance with Otsen et al. (2001), we found no significant changes in the genetic diversity of isolates associated with anthelmintic selection. However, in contrast to the high level of genetic variation in $H$. contortus, our obtained $C$. oncophora inbreeding coefficient, $F_{\mathrm{ST}}$, was low, suggesting no genetic differentiation. This agrees with the results from Höglund et al. (2006) and could mean that, if genetic resistance establishes regionally, then a rapid spread of resistance development would be enabled within the equivalent genetic pool.

In conclusion, comparison of putative Con-pgp-9 expression before and after IVM treatment showed no significant difference between the tested groups, but some tendency towards increasing expression in male as compared to female worms. Additional research is required to elucidate whether AR observed in $C$. oncophora involves increased expression and activity of PGP or whether this is related to some other transmembrane efflux transporter or metabolic enzyme.

Acknowledgments The authors would like to thank PARASOL and GLOWORM (EU projects) for the financial support. We also thank Mr. Husam Babokir who contributed with technical assistance, and associate professor David Morrisson for advice in statistical analysis.

Open Access This article is distributed under the terms of the Creative Commons Attribution License which permits any use, distribution, and reproduction in any medium, provided the original author(s) and the source are credited.

\section{References}

Anonymous (1986) Manual of veterinary parasitological laboratory techniques. Reference book 418. Her Majesty's Stationary Office, London, $\mathrm{p} 166$

Ardelli BF, Prichard RK (2008) Effects of ivermectin and moxidectin on the transcription of genes coding for multidrug resistance associated proteins and behaviour in Caenorhabditis elegans. J Nematol 40:290298

Blackhall WJ, Liu HY, Xu M, Prichard RK, Beech RN (1998a) Selection at a P-glycoprotein gene in ivermectin- and moxidectin-selected strains of Haemonchus contortus. Mol Biochem Parasitol 95(2):193-201

Blackhall WJ, Pouliot JF, Prichard RK, Beech RN (1998b) Haemonchus contortus: selection at a glutamate-gated chloride channel gene in ivermectin- and moxidectin-selected strains. Exp Parasitol 90(1):4248. doi:10.1006/expr.1998.4316

Blackhall WJ, Prichard RK, Beech RN (2003) Selection at a gammaaminobutyric acid receptor gene in Haemonchus contortus resistant to avermectins/milbemycins. Mol Biochem Parasitol 131(2):137-145

Cully DF et al (1994) Cloning of an avermectin-sensitive glutamategated chloride channel from Caenorhabditis elegans. Nature 371(6499):707-711. doi:10.1038/371707a0

De Graef J et al (2013) Gene expression analysis of ABC transporters in a resistant Cooperia oncophora isolate following in vivo and in vitro exposure to macrocyclic lactones. Parasitology: 1-10 doi:10.1017/ S0031182012001849

Demeler J et al (2009) Monitoring the efficacy of ivermectin and albendazole against gastro intestinal nematodes of cattle in Northern Europe. Vet Parasitol 160(1-2):109-115. doi:10.1016/j.vetpar.2008.10.030

Demeler J, Kuttler U, von Samson-Himmelstjerna G (2010) Adaptation and evaluation of three different in vitro tests for the detection of resistance to anthelmintics in gastro intestinal nematodes of cattle. Vet Parasitol 170(1-2):61-70. doi:10.1016/j.vetpar.2010.01.032

Dent JA, Smith MM, Vassilatis DK, Avery L (2000) The genetics of ivermectin resistance in Caenorhabditis elegans. Proc Natl Acad Sci USA 97(6):2674-2679

Dicker AJ, Nisbet AJ, Skuce PJ (2011) Gene expression changes in a Pglycoprotein (Tci-pgp-9) putatively associated with ivermectin resistance in Teladorsagia circumcincta. Int J Parasitol 41(9):935-942. doi:10.1016/j.ijpara.2011.03.015

Dupuy J, Alvinerie M, Menez C, Lespine A (2010) Interaction of anthelmintic drugs with P-glycoprotein in recombinant LLC-PK1-mdr1a cells. Chem Biol Interact 186(3):280-286. doi:10.1016/j.cbi.2010.05.013

Gasbarre LC, Smith LL, Lichtenfels JR, Pilitt PA (2009) The identification of cattle nematode parasites resistant to multiple classes of anthelmintics in a commercial cattle population in the US. Vet Parasitol 166(3-4):281-285. doi:10.1016/j.vetpar.2009.08.018

Gupta S, Gollapudi S (1993) P-glycoprotein (MDR 1 gene product) in cells of the immune system: its possible physiologic role and alteration in aging and human immunodeficiency virus-1 (HIV-1) infection. J Clin Immunol 13(5):289-301

Höglund J (2010) Parasite surveillance and novel use of anthelmintics in cattle. Acta Vet Scand 52:2-5

Höglund J, Engström A, Morrison DA, Mattsson JG (2004) Genetic diversity assessed by amplified fragment length polymorphism analysis of the parasitic nematode Dictyocaulus viviparus the lungworm of cattle. Int J Parasitol 34(4):475-484. doi:10.1016/j.ijpara.2003.11.007

Höglund J, Morrison DA, Mattsson JG, Engström A (2006) Population genetics of the bovine/cattle lungworm (Dictyocaulus viviparus) based on mtDNA and AFLP marker techniques. Parasitology 133(Pt 1):89 99. doi:10.1017/S0031182006009991

Höglund J, Morrison DA, Engström A, Nejsum P, Jansson DS (2012) Population genetic structure of Ascaridia galli re-emerging in noncaged laying hens. Parasit Vectors 5:97. doi:10.1186/1756-3305-5-97 
James CE, Davey MW (2009) Increased expression of ABC transport proteins is associated with ivermectin resistance in the model nematode Caenorhabditis elegans. Int J Parasitol 39(2):213-220. doi:10.1016/j.ijpara.2008.06.009

Jones PM, George AM (2005) Multidrug resistance in parasites: ABC transporters, P-glycoproteins and molecular modelling. Int $\mathrm{J}$ Parasitol 35(5):555-566. doi:10.1016/j.ijpara.2005.01.012

Kerboeuf D, Guegnard F (2011) Anthelmintics are substrates and activators of nematode $\mathrm{P}$ glycoprotein. Antimicrob Agents Chemother 55(5):2224-2232. doi:10.1128/AAC.01477-10

Kerboeuf D, Blackhall W, Kaminsky R, von Samson-Himmelstjerna G (2003a) P-glycoprotein in helminths: function and perspectives for anthelmintic treatment and reversal of resistance. Int J Antimicrob Agents 22(3):332-346

Kerboeuf D, Guegnard F, Vern YL (2003b) Detection of Pglycoprotein-mediated multidrug resistance against anthelmintics in Haemonchus contortus using anti-human mdr1 monoclonal antibodies. Parasitol Res 91:79-85

Larsson A, Dimander SO, Rydzik A, Uggla A, Waller PJ, Höglund J (2007) A 3-year field evaluation of pasture rotation and supplementary feeding to control parasite infection in first-season grazing cattle: dynamics of pasture infectivity. Vet Parasitol 145(1-2):129-137

Lespine A, Alvinerie M, Vercruysse J, Prichard RK, Geldhof P (2008) $\mathrm{ABC}$ transporter modulation: a strategy to enhance the activity of macrocyclic lactone anthelmintics. Trends Parasitol 24(7):293298. doi:10.1016/j.pt.2008.03.011

Livak KJ, Schmittgen TD (2001) Analysis of relative gene expression data using real-time quantitative PCR and the 2(-Delta Delta C(T)) Method. Methods 25(4):402-408. doi:10.1006/meth.2001.1262

Loo TW, Clarke DM (1999) Merck Frosst Award Lecture 1998. Molecular dissection of the human multidrug resistance Pglycoprotein. Biochem Cell Biol 77(1):11-23

Lynagh T, Lynch JW (2010) A glycine residue essential for high ivermectin sensitivity in Cys-loop ion channel receptors. Int J Parasitol 40(13):1477-1481. doi:10.1016/j.ijpara.2010.07.010

Lynch M, Milligan BG (1994) Analysis of population genetic structure with RAPD markers. Mol Ecol 3(2):91-99

Martin RJ, Murray I, Robertson AP, Bjorn H, Sangster N (1998) Anthelmintics and ion-channels: after a puncture, use a patch. Int J Parasitol 28(6):849-862

McCavera S, Walsh TK, Wolstenholme AJ (2007) Nematode ligandgated chloride channels: an appraisal of their involvement in macrocyclic lactone resistance and prospects for developing molecular markers. Parasitology 134(Pt 8):1111-1121. doi:10.1017/ S0031182007000042

Nejsum P, Frydenberg J, Roepstorff A, Parker ED Jr (2005) Population structure in Ascaris suum (Nematoda) among domestic swine in Denmark as measured by whole genome DNA fingerprinting. Hereditas 142(2005):7-14. doi:10.1111/j.1601-5223.2005.01864.x

Njue AI, Hayashi J, Kinne L, Feng XP, Prichard RK (2004) Mutations in the extracellular domains of glutamate-gated chloride channel alpha3 and beta subunits from ivermectin-resistant Cooperia oncophora affect agonist sensitivity. J Neurochem 89(5):1137-1147. doi:10.1111/ j.1471-4159.2004.02379.x

Omura S (2008) Ivermectin: 25 years and still going strong. Int J Antimicrob Agents 31(2):91-98. doi:10.1016/j.jjantimicag.2007.08.023

Otsen M, Hoekstra R, Plas ME, Buntjer JB, Lenstra JA, Roos MH (2001) Amplified fragment length polymorphism analysis of genetic diversity of Haemonchus contortus during selection for drug resistance. Int J Parasitol 31(10):1138-1143

Pachnicke S (2009) Molecular mechanisms involved in anthelmintic resistance. Dissertation. A thesis submitted for the degree of Doctor of philosophy in the subject of Parasitology. Institute for Parasitology, University of Veterinary Medicine, Hannover

Prichard R (2001) Genetic variability following selection of Haemonchus contortus with anthelmintics. Trends Parasitol 17(9):445-453

Prichard RK, von Samson-Himmelstjerna G, Blackhall WJ, Geary TG (2007) Foreword: towards markers for anthelmintic resistance in helminths of importance in animal and human health. Parasitology 134(Pt 8):1073-1076. doi:10.1017/S0031182007000078

Rana AK, Misra-Bhattacharya S (2013) Current drug targets for helminthic diseases. Parasitol Res 112:1819-1831. doi:10.1007/s00436-0133383-6

Riou M, Koch C, Delaleu B, Berthon P, Kerboeuf D (2005) Immunolocalisation of an $\mathrm{ABC}$ transporter, P-glycoprotein, in the eggshells and cuticles of free-living and parasitic stages of Haemonchus contortus. Parasitol Res 96(3):142-148. doi:10.1007/ s00436-005-1345-3

Sutherland IA, Leathwick DM (2011) Anthelmintic resistance in nematode parasites of cattle: a global issue? Trends Parasitol 27(4):176-181. doi:10.1016/j.pt.2010.11.008

Troell K, Engström A, Morrison DA, Mattsson JG, Höglund J (2006) Global patterns reveal strong population structure in Haemonchus contortus, a nematode parasite of domesticated ruminants. Int $\mathrm{J}$ Parasitol 36(12):1305-1316. doi:10.1016/j.ijpara.2006.06.015

Tyden E, Tallkvist J, Tjalve H, Larsson P (2009) P-glycoprotein in intestines, liver, kidney and lymphocytes in horse. J Vet Pharmacol Ther 32(2):167-176. doi:10.1111/j.1365-2885.2008.01017.x

Vekemans X (2002) AFLP-SURV version 1.0. A Program for genetic diversity analysis with AFLP (and RAPD) population data. version 1.0. edn. Laboratoire de Génétique et Ecologie Végétale, Université Libre de Bruxelles, Belgium

Williamson SM, Storey B, Howell S, Harper KM, Kaplan RM, Wolstenholme AJ (2011) Candidate anthelmintic resistanceassociated gene expression and sequence polymorphisms in a triple-resistant field isolate of Haemonchus contortus. Mol Biochem Parasitol 180(2):99-105. doi:10.1016/j.molbiopara.2011.09.003

Wolstenholme AJ, Fairweather I, Prichard R, von Samson-Himmelstjerna G, Sangster NC (2004) Drug resistance in veterinary helminths. Trends Parasitol 20(10):469-476. doi:10.1016/j.pt.2004.07.010

Xu M, Molento M, Blackhall W, Ribeiro P, Beech R, Prichard R (1998) Ivermectin resistance in nematodes may be caused by alteration of P-glycoprotein homolog. Mol Biochem Parasitol 91(2):327-335

Zhivotovsky LA (1999) Estimating population structure in diploids with multilocus dominant DNA markers. Mol Ecol 8(6):907-913 